\title{
Endoscopic "cutting" of a trapped Dormia basket
}

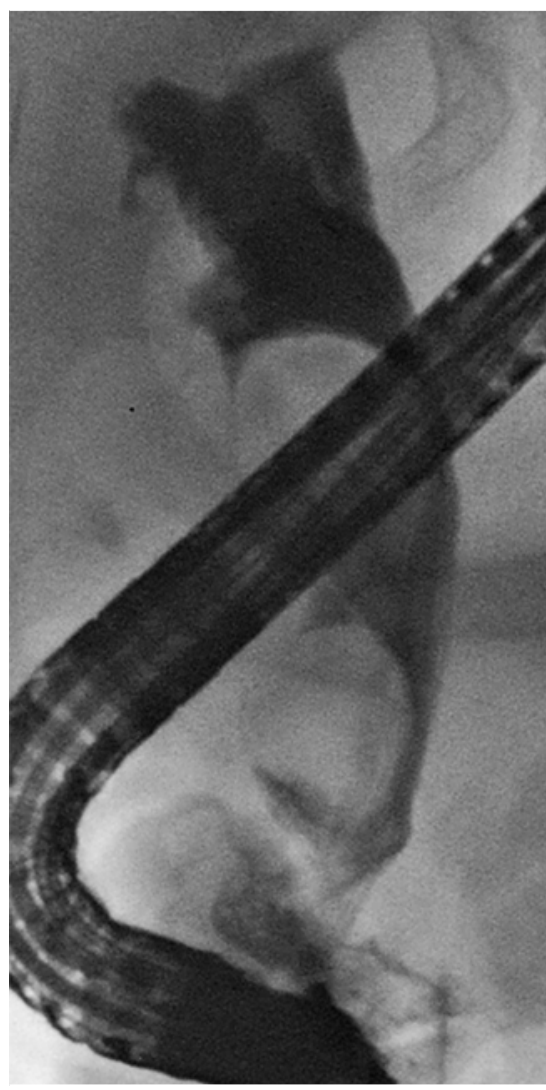

- Fig. 1 Cholangiogram showed two large bile duct stones.

Mechanical lithotripsy is effective for removal of large bile duct stones during endoscopic retrograde cholangiopancreatography (ERCP) but is a complex procedure with a risk of complications [1]. The availability of alternative techniques to extract difficult stones (i.e. endoscopic papillary large balloon dilation [EPLBD] and cholangioscopy-assisted lithotripsy) [2] has resulted in a decline in the use of mechanical lithotripsy. Nevertheless, cholangioscopy-assisted lithotripsy is an advanced technique, not widely available, and is still expensive.

Complications of mechanical lithotripsy can be challenging to manage. We describe a method of removing a trapped Dormia basket.

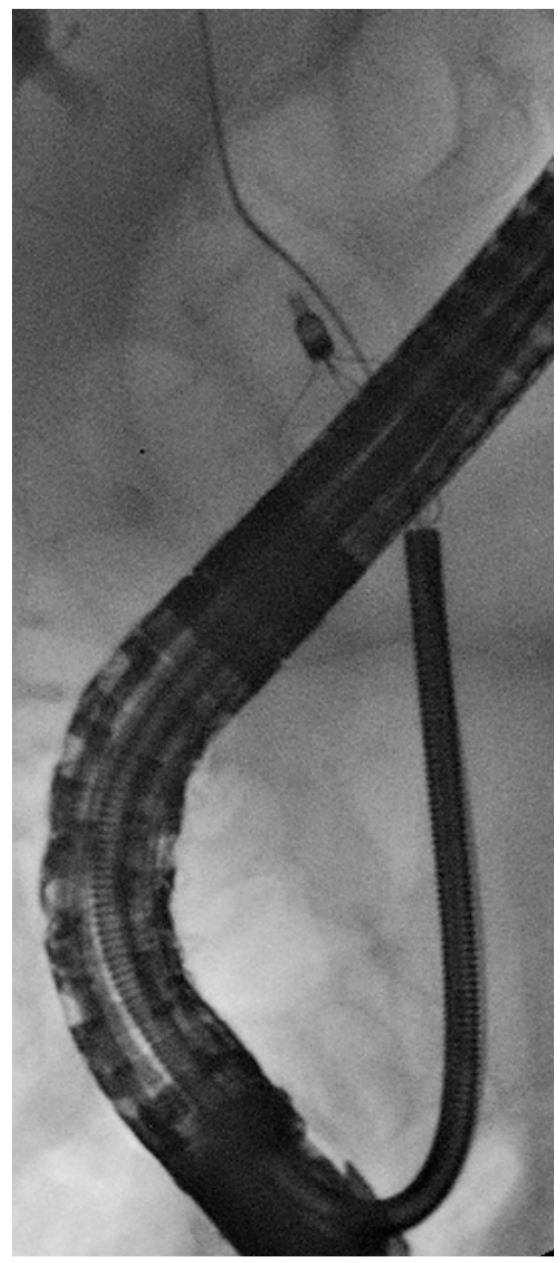

- Fig. 2 Attempted mechanical lithotripsy to remove the larger stone.

A 78-year-old woman with a history of recurrent cholangitis underwent ERCP for common bile duct stones. Two stones $(10 \times 15 \mathrm{~mm}$ and $15 \times 20 \mathrm{~mm})$ (\$Fig. 1) were seen on cholangiogram. After sphincterotomy and 15-mm EPLBD, the smaller stone was extracted using a Fogarty balloon. The larger stone could not be removed, and intra-endoscopic mechanical lithotripsy was attempted (-Fig.2); however, the Dormia wires broke near the handle of the lithotriptor despite being specially designed for mechanical lithotripsy.

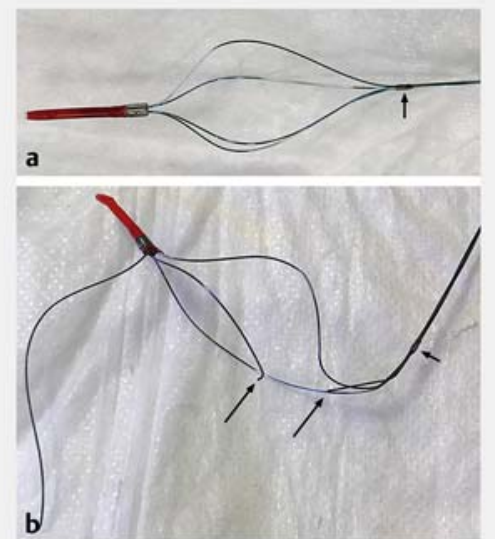

-Fig. 3 The Nitinol Dormia basket. a The basket has a crimp (arrow) that joins the four wires of the basket. $\mathbf{b}$ The wires were cut (arrow) between the crimp (arrowhead) and the tip of the basket.

The Dormia basket was made of Nitinol with a "crimp" that joins the four wires ( Fig.3a). The trapped basket was pulled closer to the papilla, making it possible to visualize the "crimp." Argon plasma coagulation (APC2; ERBE, Tübingen, Germany; Forced setting, $80 \mathrm{~W}$ ) was then used to trim the two wires between the "crimp" and the tip of the basket ( $>$ Fig.3 b, $>$ Video 1 ); the trapped Dormia was finally retrieved using another small $(10 \mathrm{~mm})$ over-the-wire basket (> Fig.4). Plastic stents were inserted near the stone and the patient was referred for cholangioscopy-assisted lithotripsy, which was successful.

The use of APC to trim the meshes of selfexpandable metal stents has been reported previously [3] and can be considered for "cutting" other endoscopic devices when necessary for their retrieval.

Endoscopy_UCTN_Code_CPL_1AK_2AF 


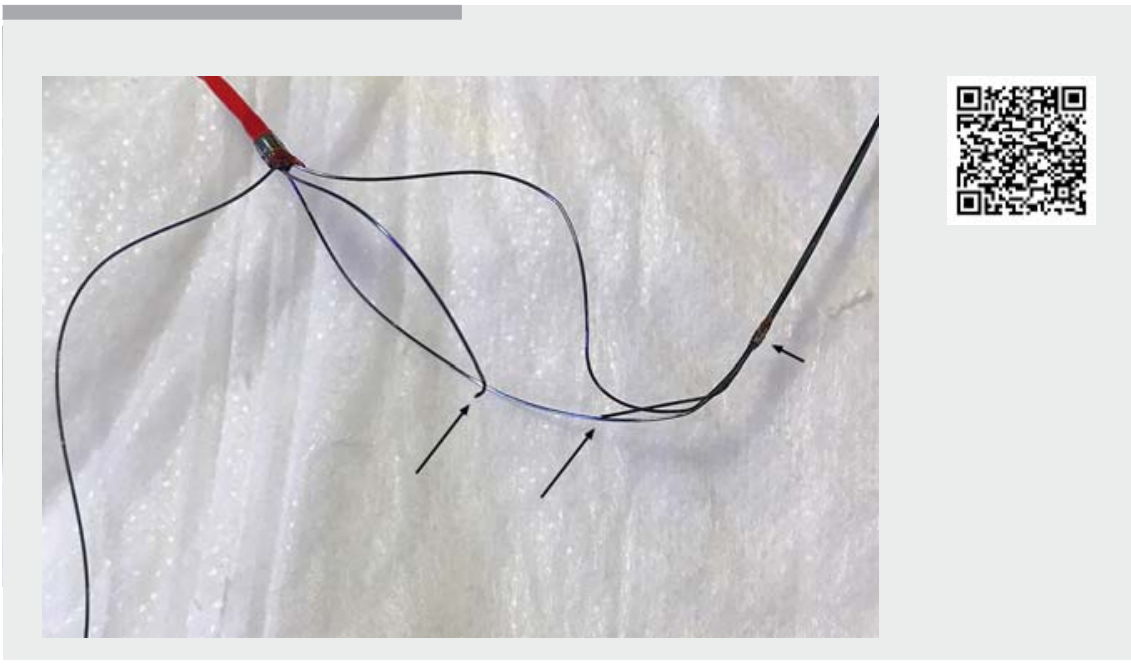

Video 1 Application of argon plasma coagulation to trim the wires of a trapped Nitinol Dormia basket for retrieval.

\section{Competing interests}

Dr. Costamagna is an advisory board member for Cook Medical, Olympus, and Ethicon, and has received research funding from Boston Scientific Corp. and Apollo Endosurgery. Dr. Tringali has been a consultant for Boston Scientific Corp. All other authors declare that they have no conflict of interest.

The authors

Andrea Tringali ${ }^{1,2}$, Giovanna Margagnoni ${ }^{3}$, Stefano Brighi' ${ }^{3}$, Guido Costamagna ${ }^{1,2}$

1 Digestive Endoscopy Unit, Fondazione Policlinico Universitario Agostino Gemelli IRCCS, Roma, Italia

2 Centre for Endoscopic Research Therapeutics and Training (CERTT), Università Cattolica del Sacro Cuore di Roma, Roma, Italia

3 Digestive Endoscopy Unit, Ospedale “F. Spaziani”, Frosinone, Italia
Corresponding author

\section{Andrea Tringali, MD, PhD}

Digestive Endoscopy Unit, Fondazione Policlinico Gemelli IRCCS - Catholic University, Largo Gemelli 8, Rome 00168, Italy

Fax: +39-06-30157220

andrea.tringali@unicatt.it

\section{References}

[1] Thomas M, Howell DA, Carr-Locke D et al. Mechanical lithotripsy of pancreatic and biliary stones: complications and available treatment options collected from expert centers. Am J Gastroenterol 2007; 102: 1896-1902

[2] Manes G, Paspatis G, Aabakken L et al. Endoscopic management of common bile duct stones: European Society of Gastrointestinal Endoscopy (ESGE) guideline. Endoscopy 2019; 51: 472-491

[3] Demarquay JF, Dumas R, Peten EP et al. Argon plasma endoscopic section of biliary metallic prostheses. Endoscopy 2001; 33: 289-290

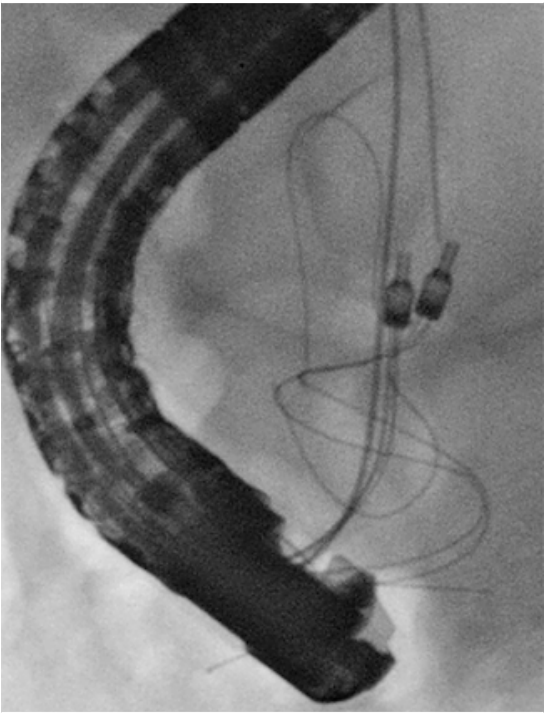

Fig. 4 Removal of the trapped Dormia with another small basket.

\section{Bibliography}

Endoscopy 2021; 53: E79-E80

DOI 10.1055/a-1196-1095

ISSN 0013-726X

published online 26.6.2020

(c) 2020. Thieme. All rights reserved.

Georg Thieme Verlag KG, Rüdigerstraße 14,

70469 Stuttgart, Germany

\section{ENDOSCOPY E-VIDEOS}

https://eref.thieme.de/e-videos

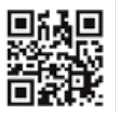

Endoscopy E-Videos is a free access online section, reporting on interesting cases and new

techniques in gastroenterological endoscopy. All papers include a high quality video and all contributions are freely accessible online.

This section has its own submission website at https://mc.manuscriptcentral.com/e-videos 